\title{
Correction to: Phlegmonous appendicitis in children is characterized by eosinophilia in white blood cell counts
}

\author{
Maximiliane I. Minderjahn ${ }^{1} \cdot$ Dag Schädlich ${ }^{1} \cdot$ Josephine Radtke ${ }^{1} \cdot$ Karin Rothe $^{1} \cdot$ Marc Reismann $^{1}$
}

Published online: 22 September 2018

(c) Children's Hospital, Zhejiang University School of Medicine 2018

\section{Correction to: World Journal of Pediatrics https://doi.org/10.1007/s12519-018-0173-3}

In the original publication, there are some errors in the labeling of the $y$-axis of the graphs in Figs. 1, 2 and 3. The corrected figures are given in this Correction.

In the "Introduction" section, the sentence in the third paragraph "The traditional view that phlegmonous appendicitis results from gangrenous inflammation ...... by Andersson et al. in 1994 [2, 3]" should read as: "The traditional view that phlegmonous appendicitis results in gangrenous inflammation ...... by Andersson et al. in 1994 [2, 3]."

In the third paragraph under the section "Results-Epidemiology": The sentence "The mean total time period from onset of symptoms until surgery was comparable in patients with phlegmonous and gangrenous appendicitis $[1.9 \pm 1.1$ (ph) vs. $1.8 \pm 1.2$ (comp); days; $P>0.01] \ldots \ldots$. (2.5 \pm 2.0 days; $P<0.0001$ and $P<0.001$, respectively)" should read as "The mean total time period from onset of symptoms until surgery was comparable in patients with

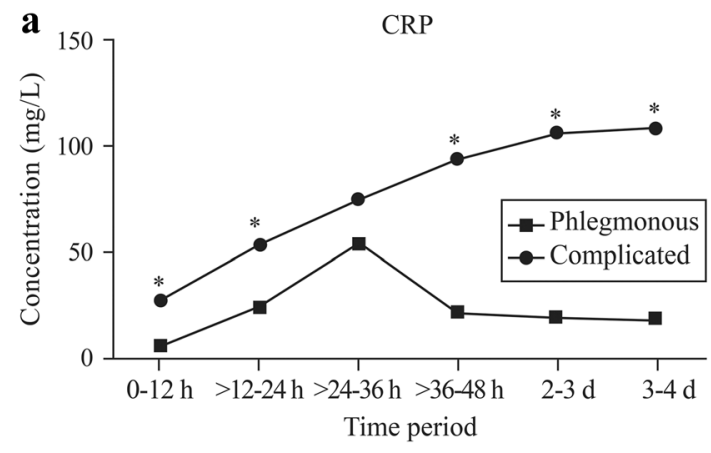

Fig. 1

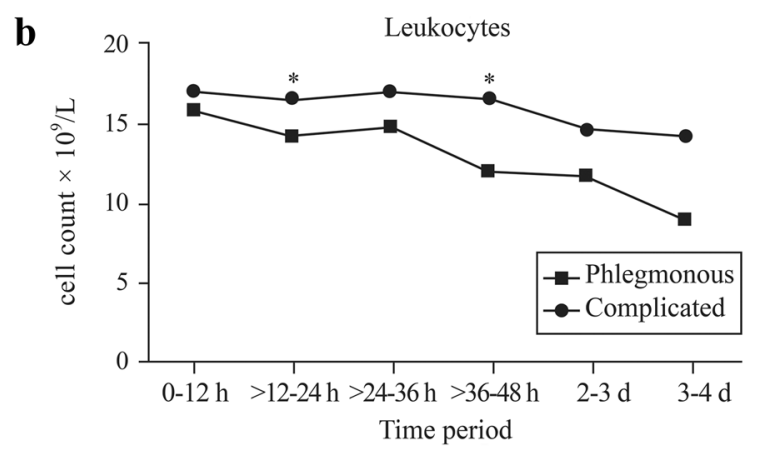

The original article can be found online at https://doi.org/10.1007/ s12519-018-0173-3.

Marc Reismann

marc.reismann@charite.de

1 Department of Pediatric Surgery, Charité-

Universitätsmedizin Berlin, Augustenburger Platz 1,

13353 Berlin, Germany 
a

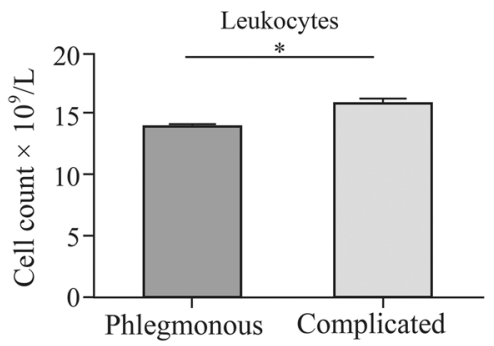

d

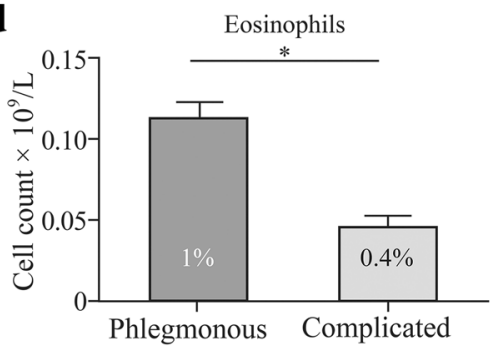

Fig. 2

a
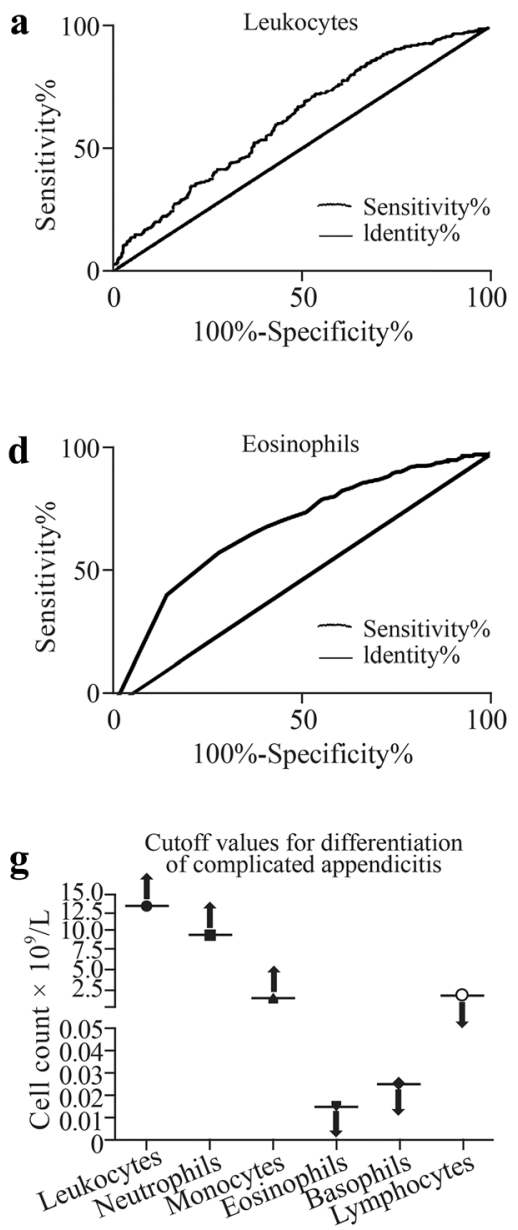

Fig. 3
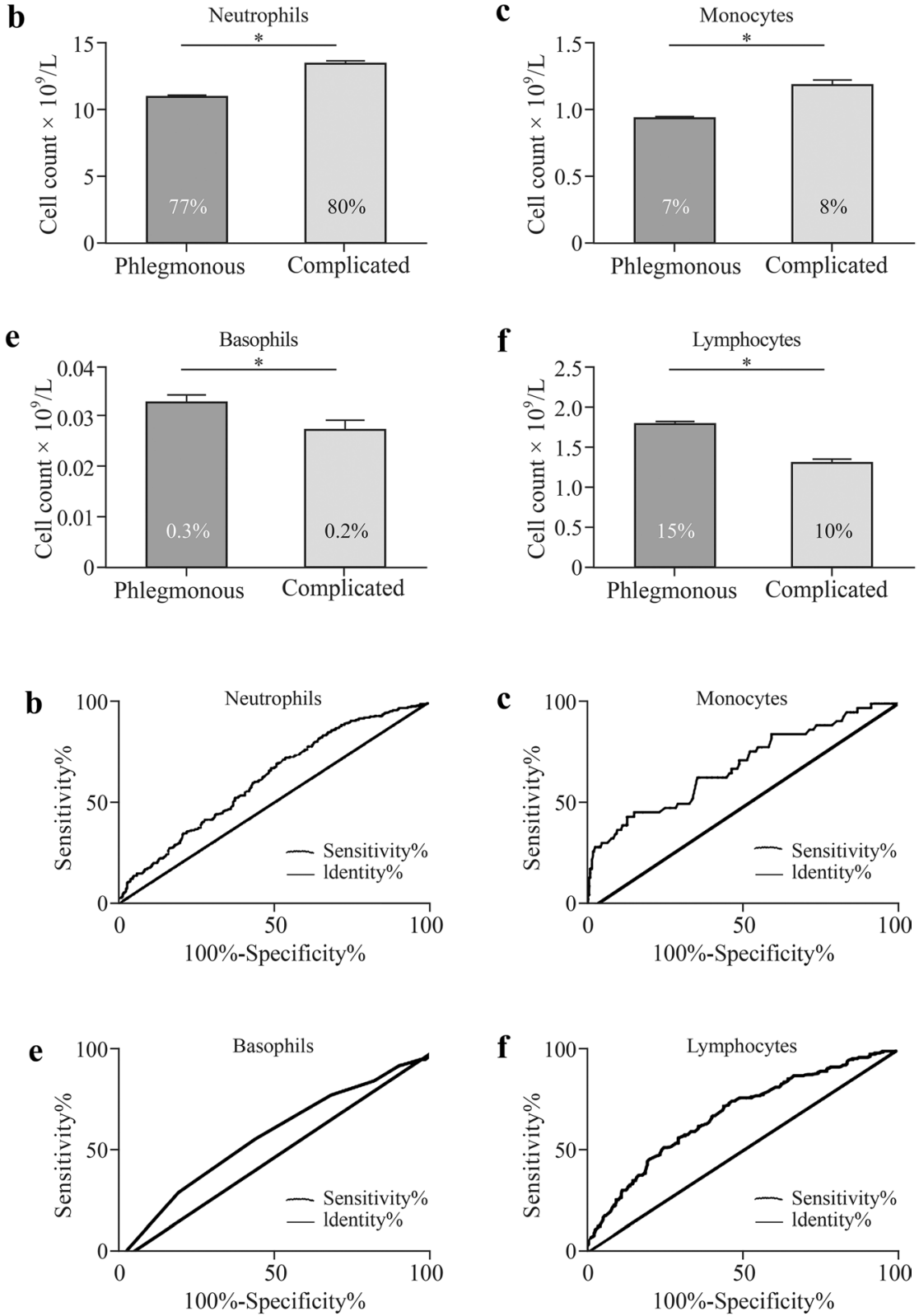
phlegmonous and gangrenous appendicitis $[1.9 \pm 1.1(\mathrm{ph})$

The original article has been corrected.

vs. $1.8 \pm 1.2(\mathrm{gg})$; days; $P>0.01] \ldots \ldots(2.5 \pm 2.0$ days;

$P<0.0001$ and $P<0.001$, respectively)". 